\title{
Valuation and Returns of Drug Development Companies: Lessons for Bioentrepreneurs and Investors
}

\author{
Daniel Tobias Michaeli ${ }^{1,2,3}\left[\right.$ Hasan Basri Yagmur ${ }^{2} \cdot$ Timur Achmadeev $^{2} \cdot$ Thomas Michaeli $^{1,3,4}(\mathbb{C}$
}

Received: 1 May 2021 / Accepted: 20 December 2021 / Published online: 11 January 2022

(c) The Author(s) 2022

\begin{abstract}
Objectives This study evaluates the association of Biopharma company valuation with the lead drug's development stage, orphan status, number of indications, and disease area. We also estimated annual returns Bioentrepreneurs and investors can expect from founding and investing in drug development ventures.

Methods SDC Thomson Reuter and S\&P Capital IQ were screened for majority acquisitions of US and EU Biopharma companies developing new molecular entities for prescription use (SIC code: 2834). Acquisition data were complemented with drug characteristics extracted from clinicaltrials.gov, the US Food and Drug Administration (FDA), and deal announcements. Thereafter, company valuations were combined with previously published clinical development periods alongside orphan-, indication-, and disease-specific success rates to estimate annual returns for investments in drug developing companies.

Results Based on a sample of 311 Biopharma acquisitions from 2005 to 2020, companies developing orphan, multi-indication, and oncology drugs were valued significantly higher than their peers during later development stages $(p<0.05)$. We also estimated significantly higher returns for shareholders of companies with orphan relative to non-orphan-designated lead drugs from Phase 1 to FDA approval $(46 \%$ vs. $12 \%, p<0.001)$. Drugs developed across multiple indications also provided higher returns than single-indication agents from Pre-Clinic to FDA approval ( $21 \%$ vs. $11 \%, p<0.001)$. Returns for oncology drugs exceeded other disease areas $(26 \%$ vs. $8 \%, p<0.001)$.

Conclusions Clinical and economic conditions surrounding orphan-designated drugs translate to a favorable financial riskreturn profile for Bioentrepreneurs and investors. Bioentrepreneurs must be aware of the upside real option value their multiindication drug could offer when negotiating acquisition or licensing agreements.
\end{abstract}

Keywords Orphan · Multi-indication · Valuation · Drug development $\cdot$ Investment · Oncology

\section{Introduction}

Large Biopharma firms are often in the spotlight of public media for bringing novel pharmaceuticals to the market. However, more than half of new drug approvals are developed externally by start-ups or research institutes [1]. While

Daniel Tobias Michaeli

danielmichaeli@yahoo.com

1 Fifth Department of Medicine, University Hospital Mannheim, Heidelberg University, Mannheim, Germany

2 TUM School of Management, Technical University of Munich, Munich, Germany

3 Department of Personalized Oncology, University Hospital Mannheim, Heidelberg University, Mannheim, Germany

4 Division of Personalized Medical Oncology, German Cancer Research Center (DKFZ), Heidelberg, Germany previously published literature focuses on the costs and timelines of the internal research and development (R\&D) process [2], in this article, we concentrate on the dynamics of the external drug development process.

A common path for a Biopharma venture to emerge is for scientists to build a business around their novel scientific discovery. These scientists are often subject matter experts in their field. Yet for their venture to succeed they also require managerial competences that extend beyond their scientific work. Specifically, soft skills coupled with managerial principles are crucial to scale a Biopharma venture $[3,4]$. Early on Bioentrepreneurs will face the challenge of securing funding for their venture from academic institutions, research grants, and investors. In other words, founders must be able to evaluate both the scientific and financial merits of their discovery. Consequently, in this study, we aim to identify key value drivers of Biopharma ventures based 
on a cross-sectional sample of 311 Biopharma acquisitions. While it is established that Biopharma firm value is mainly dependent on the lead drug's development stage [5-9], we also evaluate the association of firm valuation with the lead drug's FDA orphan designation status, number of indications, molecule type, and disease area.

On the other side, investors and large Biopharma companies must continuously find new ventures to deploy their fund's capital and commercialize new drugs [10]. They too evaluate both the scientific and financial merits of an investment proposal. Ideally the investment would yield excessbetter than average-financial returns. Consequently, the second aim of this paper is to model the risk-return characteristics of the drug development process. We will combine extracted company valuations with success rates and timelines of the drug development process to estimate financial returns. While these are not real returns from a longitudinal dataset of investments, our model permits the identification of industry trends. We will particularly evaluate whether orphan-designated, multi-indication, biologic, and oncology drugs provide excess returns for Bioentrepreneurs and investors.

\section{Materials and Methods}

\section{Data Collection}

SDC Thomson Reuter and S\&P Capital IQ were screened for majority acquisitions of Biopharma companies developing new molecular entities (NME) for therapeutic use (SIC code: 2834) from 01.01.2005 to 01.01.2020. Corporations developing generics, reformulations, medical devices, diagnostic substances, over-the-counter medicines, cannabis products, animal therapeutics as well as active pharmaceutical ingredients producers and sales of manufacturing sites were excluded. Only acquisitions with a total deal value beyond $\$ 10$ million were considered. To exclude mega mergers the sample was limited to targets with a portfolio of less than 10 NME. The geographic location was restricted to targets headquartered in the US or developed European markets. The sample contains both private and public targets.

Financial variables and acquisition characteristics were extracted from SDC Thomson Reuter and S\&P Capital IQ. Subsequently, the target's lead product's development stage, orphan designation status, number of indications, molecule type, and disease area were obtained from the US FDA database, US SEC filings, clinicaltrials.gov, and deal announcements.

\section{Valuation Metrics}

Up-front payments, maximum milestone payments (both regulatory and sales), and the overall deal value were obtained from SDC Thomson Reuter and S\&P Capital IQ in US dollars at the time of the acquisition. To ensure data validity, all company valuations were cross-checked with US SEC filings and deal announcements, if available. Valuation metrics were adjusted for inflation to 2020 values.

\section{Development Stage}

The development of human pharmaceutical products can be categorized into five distinct stages: Pre-Clinic, Phase 1, Phase 2, Phase 3, and Approved. We extracted and crosschecked the lead product's development phase from FDA marketing authorization reports, clinicaltrials.gov, US SEC filings, and deal announcements. Therapeutics in parallel Phase 1/2 (2/3) trials were categorized within the Phase 2 (3) development stage.

\section{Orphan Designation}

All therapeutics were checked for orphan designations issued by the FDA. Thereby therapeutics were classified as "orphan" and "non-orphan".

\section{Number of Indications}

We also extracted the number of indications a therapeutic is being developed for using clinicaltrials.gov. Consequently, therapeutics developed for one disease were categorized as "single-indication" and therapeutics developed for more than one disease were classified as "multi-indication".

\section{Molecule Type}

The lead therapeutics molecule type was furthermore classified into "small-molecule" and "biologics or gene/cell therapies".

\section{Disease Area}

Lead therapeutics were furthermore classified into disease areas according to the most advanced indication. Categories include oncology, central nervous system (CNS), and others (immunology, infectious disease, cardiovascular, dermatology, internal medicine, ophthalmology).

\section{Statistical Analysis}

First, mean company valuations $\pm 95 \%$ confidence intervals (CI) for orphan designation status, disease area, number 
Table 1 Input parameters for the estimation of investment multiples and returns

\begin{tabular}{llllllll}
\hline & Mean & \multicolumn{1}{c}{ 95\% CI } & Source & $\sigma$ & $\alpha$ & $\beta$ & Distribution \\
\hline Company valuation (\$ millions) & & & & & & & \\
Pre-Clinic & 88 & $(57-119)$ & a & 15.65 & 31.54 & 2.79 & Gamma \\
Phase 1 & 399 & $(211-498)$ & a & 66.78 & 28.17 & 12.58 & Gamma \\
Phase 2 & 734 & $(436-930)$ & a & 112.14 & 31.28 & 21.84 & Gamma \\
Phase 3 & 1656 & $(996-2527)$ & a & 369.13 & 22.77 & 77.36 & Gamma \\
Approved & 2496 & $(1582-3355)$ & a & 432.58 & 32.57 & 75.80 & Gamma \\
Success rate (\%) & & & & & & & \\
Pre-Clinic to Phase 1 & 32.0 & $(28.8-35.2)$ & {$[15]$} & 1.60 & 271.68 & 577.32 & Beta \\
Phase 1 to Phase 2 & 75.8 & $(68.2-83.4)$ & {$[11]$} & 3.79 & 96.04 & 30.66 & Beta \\
Phase 2 to Phase 3 & 55.6 & $(50.0-61.2)$ & {$[11]$} & 2.78 & 177.04 & 141.38 & Beta \\
Phase 3 to Approved & 67.7 & $(60.9-74.5)$ & {$[11]$} & 3.39 & 128.52 & 61.32 & Beta \\
Development period (years) & & & & & & \\
Pre-Clinic to Phase 1 & 1.00 & $(0.75-1.25)$ & {$[16]$} & 0.13 & 64 & 0.016 & Gamma \\
Phase 1 to Phase 2 & 1.50 & $(1.13-1.88)$ & {$[16]$} & 0.19 & 64 & 0.023 & Gamma \\
Phase 2 to Phase 3 & 2.50 & $(1.88-3.13)$ & {$[16]$} & 0.31 & 64 & 0.039 & Gamma \\
Phase 3 to Approved & 2.50 & $(1.88-3.13)$ & {$[16]$} & 0.31 & 64 & 0.039 & Gamma \\
\hline
\end{tabular}

Distinct company valuations and success rates by orphan designation status, number of indications, molecule type, and disease area are enclosed in Supplementary Table e1. Company valuations include up-front and milestone payments and were inflation adjusted to 2020 values

${ }^{a}$ Mean company valuations were calculated from our dataset of 311 Biopharma acquisitions of indications, and molecule type were calculated within each development stage. A non-parametric bootstrapped resampling with replacement (1000 iterations) was conducted to calculate mean company valuations and their respective $95 \%$ CI in our sample. Thereafter, investment multiples and returns were estimated based on mean company valuations, development stage success rates, and development periods (Table 1).

\section{Company Valuation}

Mean company valuations were compared by orphan designation status, disease area, number of indications, and molecule type within development stages based on non-parametric bootstrapped $t$ tests (resampling of 1000 iterations with replacement). Company valuations were calculated as the sum of the up-front payments and all future milestone payments. Valuations were visualized using beeswarm plots.

Data on company valuations were available for 300 of the 311 collected acquisitions. The analysis of mean valuations and the multiple and return calculation consequently excluded 11 observations to arrive at a final sample of 300 Biopharma acquisitions. No missing data were observed for lead product characteristics, e.g., FDA orphan status, number of indications, molecule type, and disease area.

\section{Estimating Investment Multiples}

We subsequently estimated multiples Bioentrepreneurs and investors could expect from investments into development stage Biopharma ventures. In the finance industry, investment multiples compare a company's valuation at the time of sale to a company's valuation at the time of purchase. Consequently, we estimated investment multiples in the Biopharma context by dividing the mean company valuation of development stage Phase $j$ by the mean company valuation of development stage Phase $i$ (Eq. 1). To account for clinical trial failures, investment multiples were adjusted for development stage specific success rates. Clinical success rates were extracted from Wong et al. [11], given that they use the largest sample size, overlap with our study period, and employ the most relevant path-by-path methods - in contrast to other estimations which follow a phase-by-phase methodology [12-14]. Pre-Clinic to clinic success rates were extracted from Takebe et al. who analyzed 798 drug discovery projects in the US [15]. For example, the mean valuation of biopharmaceutical companies with Phase 2 therapeutics ( $\$ 683$ million) was divided by the mean valuation of companies with Phase 1 products ( $\$ 354$ million). This quotient was thereafter adjusted by the success rate to progress from Phase 1 to $2(75.8 \%)$ to arrive at the investment multiple (1.5x). 
Multiple $_{\text {Phase } i \text { to } j}=\frac{\text { Company Valuation }_{\text {Phase } j}}{\text { Company Valuation }} *$ Success Rase $i_{\text {Rate }}$ Phase $i$ to $j$

Stage-, indications-, biologic-, disease-, and orphanspecific means for company valuations and success rates were applied to estimate and compare investment multiples and returns within the respective categories. For instance, distinct Phase 1 to 2 (96.1\% vs. $75.8 \%)$, Phase 2 to $3(86.1 \%$ vs. $55.6 \%)$, and Phase 3 to Approved $(63.5 \%$ vs. $67.7 \%$ ) success rates were used for orphan vs. nonorphan-designated therapeutics. Similarly, distinct Phase 1 (\$227 vs. \$370 million), Phase 2 (\$744 vs. \$673 million), Phase 3 (\$2166 vs. \$1648 million), and Approved (\$3703 vs. \$1964 million) company valuations were used for orphan vs. non-orphan therapeutics. Employed success rates and company valuations are enclosed in Supplementary Tables e 1 and e3, respectively.

\section{Estimating Investment Returns}

Finally, annual returns Bioentrepreneurs and investors can expect from investments into development stage Biopharma companies were estimated by linking the previously calculated investment multiple to the mean development time of the respective development stage. Mean development periods were extracted for Pre-Clinic to Phase 1 (1.0 years), Phase 1 to 2 (1.5 years), Phase 2 to 3 (2.5 years), and Phase 3 to Approved (2.5 years) from previous literature [16].

\section{Results}

A total of 2106 unique Biopharma acquisitions were identified in the SDC Thomson Reuter $(n=1427)$ and S\&P Capital IQ $(n=679)$ databases between 01.01.2005 and 01.01.2020. Further restricting the search to companies developing NME for human prescription use led to final sample of 311 Biopharma company valuations. Most acquired companies were developing a lead product in Phase $2(33 \%)$ or already commercialized the lead product $(20 \%)$. Approximately one third of lead products were developed across multiple indications, $21 \%$ were classified as biologics or gene/cell therapy, and $21 \%$ received FDA orphan designation status. Most acquisitions focused on oncology (30\%), CNS (16\%), and infectious diseases therapies (11\%). More detailed descriptive statistics for the entire sample can be found in Supplementary Table e2.

\section{Orphan Designation Status}

Company valuations of orphan and non-orphan-designated therapeutics did not significantly differ for Phase 1 (\$227 vs. $\$ 370$ million, $p=0.257$ ), Phase 2 (\$744 vs. $\$ 673$ million, $p=0.373$ ), and Phase 3 (\$2166 vs. \$1648 million, $p=0.317$; Fig. 1). Company valuation was $\$ 3703$ million (95\%CI 1147-6259) with orphan and \$1964 million (95\%CI 1331-2597) with non-orphan-designated Approved therapeutics $(p<0.05)$. Estimated multiples of investments in com-

Investment Return ${ }_{\text {Phase } i \text { to } j}=\left(\text { Multiple }_{\text {Phase } i \text { to } j}\right)^{\text {Mean Development Time }_{\text {Phase } i}}-1$

\section{Sensitivity Analysis}

We conducted a probabilistic sensitivity analysis in Microsoft EXCEL to account for uncertainty surrounding point estimates of company valuation, success rates, and development stage length. Therefore, input parameters for the calculation of investment multiples and returns were drawn by random sampling from their defined distribution displayed in Table 1. Thereby this sampling method permitted the simultaneous variations in considered input parameters. This probabilistic analysis features the simulation of 1,000 investments per variable category.

Data were stored in Microsoft EXCEL and analyzed using STATA SE Version 15.1. For the two-factorial analysis of variance, ANOVA with Dunnett's/Sidak's test was applied. A two-tailed probability value $<0.05$ was considered significant. panies with orphan compared to non-orphan-designated therapeutics were significantly higher across all development stages $(p<0.001)$. Similarly, estimated returns of orphandesignated investments significantly exceeded returns of non-orphan investments for Phase 1 to 2 (120\% vs. $25 \%$, $p<0.001)$, Phase 2 to 3 (46\% vs. $14 \%, p<0.001)$ and Phase 3 to Approved ( $4 \%$ vs. $-8 \%, p<0.001$ ).

Bioentrepreneurs and investors that keep their equity stake in a company with an orphan-designated product from Phase 1 until FDA approval can expect to increase their initial capital by $7.2 x$ (95\%CI 5.6-9.0) which translates to annual returns of $46 \%$ (95\% CI 37-56) after adjusting for drug failures (Table 2). In contrast, a similar investment in companies developing nonorphan-designated products would increase the initial capital by only $2.1 x(95 \%$ CI $1.6-2.6, p<0.001)$ at annual returns of $12 \%(95 \%$ CI $8-16, p<0.001)$.

\section{Number of Indications}

Valuations of companies developing multi-indication relative to single-indication lead drugs were significantly higher 


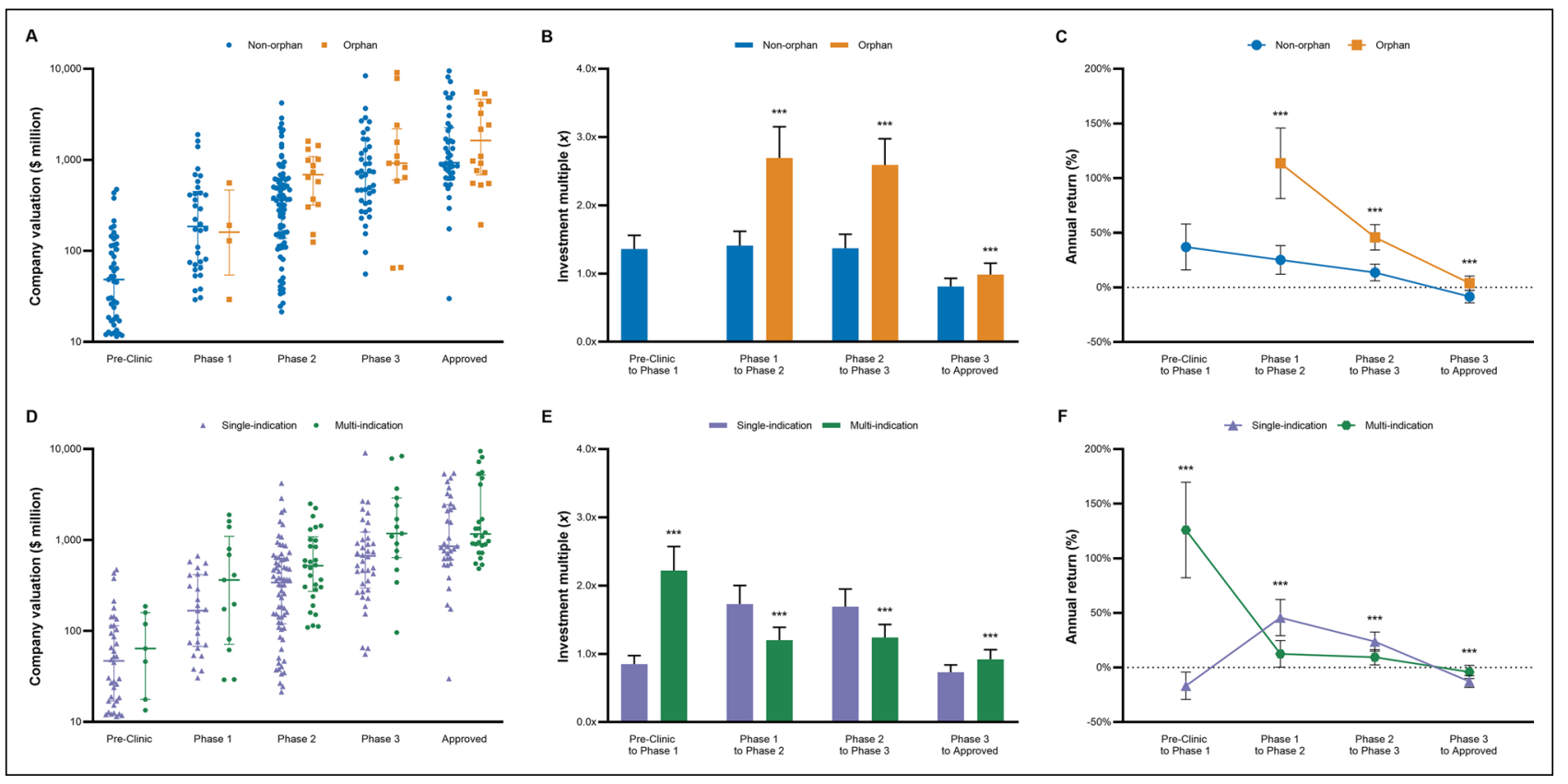

Fig. 1 Company valuation, investment multiples, and annual returns by lead drug's FDA orphan designation status and number of indications. Graphs in the first row compare the valuation (A), investment multiples (B), and annual returns $(\mathbf{C})$ for companies with orphan- and non-orphan-designated lead drugs by development stage. Graphs in the second row compare the valuation (D), investment multiples $(\mathbf{E})$, and returns (F) for companies with multi-indication and singleindication lead drugs by development stage. Valuation data from our

for Phase 1 ( $\$ 594$ vs. $\$ 230$ million, $p<0.05$ ), Phase 2 ( $\$ 1058$ vs. $\$ 522$ million, $p<0.05$ ), and Approved (\$3438 vs. $\$ 3438$ million, $p<0.01$ ), yet not Pre-Clinic ( $\$ 87$ vs. $\$ 88$ million, $p=0.484$ ) and Phase 3 ( $\$ 2249$ vs. $\$ 1578$ million, $p=0.208$ ) development stages. However, estimated multiples of investments in companies with multi-indication relative to single-indication therapeutics were only higher for Pre-Clinic to Phase 1 and Phase 3 to Approved investments periods $(p<0.001)$. For Phase 1 to 2 and Phase 2 to 3, investment multiples of companies with single-indication therapeutics outpace multi-indication products $(p<0.001)$. Similarly, estimated returns were higher for investments in companies with multi-indication relative to single-indication therapeutics for Pre-Clinic to Phase 1 (126\% vs. $-16 \%, p<0.001)$ and Phase 3 to Approved ( $-4 \%$ vs. $-12 \%, p<0.001$ ), yet not for Phase 1 to $2(12 \%$ vs. $45 \%, p<0.001)$, Phase 2 to 3 (9\% vs. $24 \%, p<0.001)$.

Equity stakes in Biopharma companies with multi-indication lead products increased by $2.9 x$ (95\% CI 2.3-3.7) yielding annualized returns of $21 \%$ (95\% CI 15-29)—assuming shareholders keep their stakes from Pre-Clinic to FDA approval (Table 2). In contrast, single-indication lead products only provided an overall investment multiple of $1.7 x$ sample of 311 Biopharma acquisitions (2005-2020) were inflation adjusted to 2020 values and combined with previously published success rates and development periods to calculate multiples and returns $[11,16]$. No valuation data exist for the Pre-Clinic orphan category given that the FDA only issues the orphan designation status after IND approval. $P$ values calculated based on ANOVA with Dunnett's test: $* p<0.05, * * p<0.01, * * * p<0.001$. FDA US Food and Drug Administration

(95\%CI $1.3-2.2, p<0.001)$ and annualized returns of $11 \%$ $(95 \%$ CI $7-14, p<0.001)$.

\section{Molecule Type}

Companies developing biologics or gene and cell therapies were valued higher relative to small-molecules during PreClinic ( $\$ 109$ vs. $\$ 71$ million, $p<0.05$ ), Phase 1 ( $\$ 341$ vs. $\$ 325$ million, $p=0.139$ ), Phase 2 (\$811 vs. $\$ 517$ million, $p<0.05$ ), and Phase 3 ( $\$ 2,249$ vs. $\$ 1,578$ million, $p=0.103$ ) yet not Approved development stages (\$2088 vs. \$2105 million, $p=0.161)$. However, estimated returns for investments in companies with biologics or gene and cell therapies were lower for Pre-Clinic to Phase 1 (18\% vs. $46 \%, p<0.001)$, higher for Phase 1 to 2 (93\% vs. $23 \%, p<0.001)$, the same for Phase 2 to 3 ( $14 \%$ vs. $15 \%, p=0.53$ ), and lower for Phase 3 to Approved ( $-29 \%$ vs. $11 \%, p<0.001)$ development stages relative to small-molecules (Fig. 2).

Bioentrepreneurs and investors that keep their equity stake in a company with a biologic or gene therapeutic lead product from Phase 1 until FDA approval can expect to increase their initial capital by $1.8 x(95 \% \mathrm{CI} 1.4-2.2)$ which translates to annual returns of $16 \%$ (95\%CI 11-21) after adjusting for drug failures (Table 2). In contrast, a 
Table 2 Estimated multiples and returns for investment in drug development Biopharma companies

\begin{tabular}{|c|c|c|c|c|c|c|}
\hline & \multicolumn{3}{|c|}{ Investment multiple $(x)$} & \multicolumn{3}{|c|}{ Annual return (\%) } \\
\hline & Value & $95 \% \mathrm{CI}^{\mathrm{a}}$ & $p$ value & Value (\%) & $95 \% \mathrm{CI}^{\mathrm{a}}$ & $p$ value \\
\hline \multicolumn{7}{|c|}{ FDA orphan designation status } \\
\hline Orphan & $7.2 x$ & $(5.6-9.0)$ & $<0.001$ & 46 & $(37-56)$ & $<0.001$ \\
\hline Non-orphan & $2.1 x$ & $(1.6-2.6)$ & & 12 & $(8-16)$ & \\
\hline \multicolumn{7}{|l|}{ Number of indications } \\
\hline Multi-indication & $2.9 x$ & $(2.3-3.7)$ & $<0.001$ & 21 & $(15-29)$ & $<0.001$ \\
\hline Single-indication & $1.7 x$ & $(1.3-2.2)$ & & 11 & $(7-14)$ & \\
\hline \multicolumn{7}{|l|}{ Molecule type } \\
\hline $\begin{array}{l}\text { Biologic OR gene/ } \\
\text { cell therapy }\end{array}$ & $1.8 x$ & $(1.4-2.2)$ & $<0.001$ & $16 \%$ & $(11-21)$ & $<0.001$ \\
\hline Small-molecule & $3.6 x$ & $(2.8-4.5)$ & & 19 & $(15-25)$ & \\
\hline \multicolumn{7}{|l|}{ Disease area } \\
\hline Oncology & $4.3 x$ & $(3.5-5.4)$ & $<0.001$ & 26 & $(21-33)$ & $<0.001$ \\
\hline CNS & $2.6 x$ & $(2.0-3.2)$ & $<0.001$ & 17 & $(13-22)$ & $<0.001$ \\
\hline Other $^{\mathrm{b}}$ & $1.5 x$ & $(1.2-1.9)$ & & 8 & $(4-11)$ & \\
\hline Overall & $2.6 x$ & $(2.0-3.3)$ & & 15 & $(11-19)$ & \\
\hline
\end{tabular}

Multiples and annual returns were estimated assuming an investment horizon from Pre-Clinic until FDA approval. Valuation data from our sample of 311 Biopharma acquisitions (2005-2020) were inflation adjusted to 2020 values and combined with previously published success rates and development periods to calculate multiples and returns $[11,16]$.

FDA US Food and Drug Administration, CNS Central nervous system

${ }^{a} 95 \%$ confidence intervals were calculated based on empirical 2.5 th and 97.5 th percentiles from the conducted sensitivity analysis

${ }^{\mathrm{b}}$ The disease category other includes immunology, infectious disease, cardiovascular, dermatology, internal medicine, and ophthalmology similar investment in companies developing small-molecule drugs would see their capital grow by $3.6 x$ (95\% CI $2.8-4.5, p<0.001)$ at annual returns of $19 \%(95 \%$ CI $15-25$, $p<0.001)$.

\section{Disease Area}

Companies with oncology drugs were valued significantly higher during Phase 2 development $(\$ 1068, p<0.05)$, while companies with CNS lead drugs ( $\$ 314$ million, $p<0.001$ ) were valued lower than other companies ( $\$ 607$ million). Simulated returns of investments into oncology relative to CNS lead drugs were significantly higher for Pre-Clinic to Phase 1 (89\% vs. $13 \%, p<0.001)$, Phase 1 to Phase 2 (66\% vs. $2 \%, p<0.001)$, Phase 3 to Approved $(10 \%$ vs. $-11 \%$, $p<0.001$ ), yet not Phase 2 to 3 ( $-5 \%$ vs. $57 \%, p<0.001$ ).

Assuming an investment horizon from Pre-Clinic to FDA approval, founders and capital providers of Biopharma companies with oncology therapeutics can expect to increase their invested capital to a greater extent compared to companies developing CNS and other therapeutic agents $(p<0.001)$. Estimated annual returns from Pre-Clinic to FDA approval were 26\% (95\%CI 21-33) for oncology, $17 \%$ (95\%CI 13-22) for CNS, and 8\% (95\%CI 4-11) for other lead therapeutics (Table 2).

\section{Discussion and Conclusion}

This study first assessed the association of Biopharma company valuation with development stage, FDA orphan designation status, number of indications, molecule type, and disease area based on a sample of 311 Biopharma acquisition from 2005 to 2020 . Thereafter, company valuations were combined with previously published clinical development periods and success rates to estimate investment multiples and annual returns. Orphan-designated (46\%), oncology (26\%), CNS (17\%), multi-indication (21\%), and smallmolecule (19\%) drugs were projected to provide significantly higher than average (15\%) annual returns to company shareholders holding equity stakes from Pre-Clinic to FDA approval $(p<0.001)$. These results provide Bioentrepreneurs with first insights into the valuation and potential of their ventures. On the other side, results educate financial and strategic financiers on investment opportunities with favorable risk-return profiles.

Our dataset illustrates that Biopharma company valuation is mainly driven by the lead product's development stage. This is in line with previous studies investigating Biopharma acquisitions and therapeutic licensing agreements $[6,7,17]$. Our calculations also demonstrate downward sloping annual returns for advanced drug development 


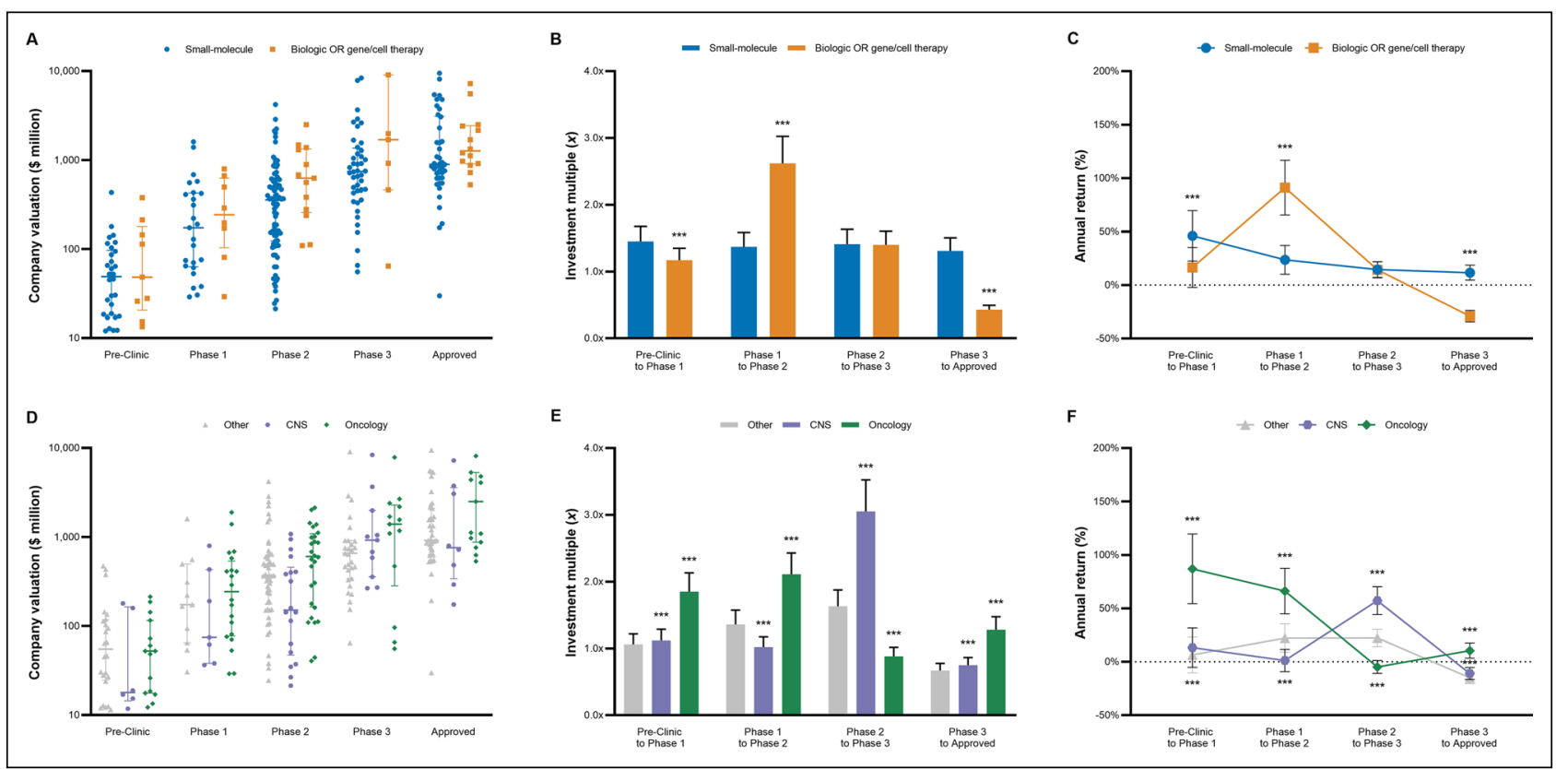

Fig. 2 Company valuation, investment multiples, and annual returns by lead drug's molecule type and disease area. Graphs in the first row compare the valuation (A), investment multiples (B), and annual returns $(\mathbf{C})$ for companies with biologics or gene/cell therapies and small-molecule lead drugs by development stage. Graphs in the second row compare the valuation $(\mathbf{D})$, investment multiples $(\mathbf{E})$, and returns (F) for companies with lead drugs in oncology, CNS, and other disease areas by development stage. Valuation data from our

stages (Supplementary Figure e1). Assuming annual returns are correlated to an investment's risk, this result implies risk is unequally distributed across the drug development process. This observation is coherent with expectations given that the pre-clinical drug discovery process and early clinical development are associated with several unknown factors and incur higher attrition rates than late-stage clinical development $[11,16]$. The more pre-clinical and clinical data are available on a drug, the lower the uncertainty and also the risk of failure, resulting in diminished returns. Overall, we calculated annual returns of $15 \%$ throughout the drug development process. This is slightly higher than previous estimates of mean industry returns for new drug introductions of $11.5 \%$ [18]. These estimates are based on new drug launches from the 1990s in large, publically listed Biopharma companies, whereas our estimate is derived from riskier acquisitions of private and public small to medium-sized Biopharma ventures from 2005 to 2020 .

In contrast to Rooswinkel et al. [19], our dataset of 311 Biopharma acquisitions demonstrates that late-stage valuations were significantly higher for companies developing orphan relative to non-orphan lead products. Accordingly, we also estimated higher investment multiples and returns for shareholders of companies with orphan relative sample of 311 Biopharma acquisitions (2005-2020) were inflation adjusted to 2020 values and combined with previously published success rates and development periods to calculate multiples and returns $[11,16]$. The disease category other includes immunology, infectious disease, cardiovascular, dermatology, internal medicine, and ophthalmology. $P$ values calculated based on ANOVA with Dunnett's test (Sidak's test for disease area): ${ }^{*} p<0.05,{ }^{*} p<0.01, * * * p<0.001$. CNS central nervous system

non-orphan-designated lead products from Phase 1 to FDA approval (46\% vs. $12 \%, p<0.001)$. Several reasons may help to explain this observation. Orphan drugs possess favorable economics given the lower clinical and FDA attrition rates, firmer and prolonged market exclusivity periods, financial R\&D incentives, expedited development and FDA approval periods, swift market penetration, and greater reimbursement prices [12, 20, 21]. Consequently, Bioentrepreneurs developing orphan-designated products confidently negotiate higher company valuations with financial investors. On the other side, investors may particularly seek to invest in orphan therapeutic as their unique economics translate to a favorable financial risk-return profile.

In 2019, the 10 highest grossing drugs were all authorized and commercialized across more than one therapeutic indication. Accordingly, results demonstrate that late-stage valuations were significantly higher for companies developing multi-indication relative to single-indication lead products. Similarly, we calculated that investment in pre-clinical companies with multi-indication lead products yield annual returns of $21 \%$ until FDA approval, whereas single-indication products only provide a return of $11 \%$ per year. Multiindication therapeutics provide companies with an upside option to develop and commercialize the drug across several 
diseases if it proofs to be safe and efficacious in initial trials. Additionally, early drug discovery efforts and timelines can be dynamically offset as they are only undertaken once per drug [22]. Furthermore, companies may engage in the sequencing of indications according to clinical benefit and patient population in order to establish higher drug prices and revenues under prevailing single price policies [23-25]. Consequently, Bioentrepreneurs must be aware of the upside real option value their therapeutic could offer to large Biopharma corporations when engaging in acquisition or licensing deals. Oppositely, strategic investors can benefit from the large market potential and favorable risk-return profile of multi-indication products.

The collected dataset of 311 Biopharma acquisitions did not reveal any significant valuation difference for companies with small-molecules compared to biologic or gene/cell therapy lead products. Nonetheless, we estimated that shareholders of Biopharma companies developing small-molecules can expect higher returns than companies developing biologics or gene/cell therapies ( $19 \%$ vs. $16 \%, p<0.001)$. This result is surprising as one might expect that the often superior clinical safety and efficacy profile of biologics and gene/cell therapeutics-which frequently permit the treatment or even cure of previously untreatable disease-would translate into a greater economic and financial benefit [12, 26-28]. Nonetheless, these clinical benefits could be offset by large initial investment outlay, higher production cost, inconvenient administration routes, and reimbursement hurdles often faced by biologics and gene/cell therapies [29, 30]. Consequently, purely financial investors should be cautious about venture opportunities of biologics and gene/cell therapies. In contrary, large Biopharma corporations could potentially benefit from strategic investments into such technologies as this provides them access to the capabilities and human capital of the innovative venture [31].

Small and large Biopharma ventures alike frequently focus their R\&D efforts on disease areas with a high unmet patient need-oncology and CNS [7, 32]. However, our dataset did not exhibit a significant difference in company valuation according to therapeutic area. Nonetheless, our calculations show higher returns for shareholders with oncology (26\%) and CNS (17\%) products relative to other $(8 \%)$ therapeutic areas $(p<0.001)$ from Pre-Clinic to FDA approval. This discrepancy might have multifactorial reasons. From a clinical perspective, oncology drugs offer a survival benefit for patients and often also improve quality of life [33]. In contrast, drugs in other areas mostly improve patients' quality of life without a proven effect on overall survival. Consequently, higher annual treatment costs and drug prices are observed for cancer drugs [34]. While some authors argue that these high prices are justified by providing clinical value to patients in areas of high unmet, Prasad et al. argue that the observed prices cannot be explained by rational arguments such as $R \& D$ costs and the absence of treatment alternatives [35]. As a result, Biopharma companies stand to make a profit on this mismatch between high prices yet arguably marginal benefit for patients [36]. Additionally, many cancer drugs are launched for rare diseases, whereby Biopharma companies realize the previously discussed favorable economics of the FDA orphan designation status. Moreover, Biopharma companies could profit from launching me-too drugs which are priced similar to first-in-class agents yet consume less R\&D resources [37]. A combination of all these factors help to explain the estimated higher returns of investments in companies developing oncology drugs.

\section{Strengths \& Limitations}

Strengths of this study include its large sample size, uniquely detailed drug characteristics, and employed modeling technique. However, this study also has several limitations. First, non-disclosed information may bias results. Specifically, undisclosed acquisitions of very early-stage pre-clinical corporations may not be released and thereby overestimate company valuations of the pre-clinical development stage, which in turn cause returns to be underestimated.

Second, investment multiples and returns were estimated based on a cross-section of company valuations. Detailed longitudinal data entailing a company's valuation alongside its drug's development stage and characteristics would be necessary to correctly evaluate real returns received by Bioentrepreneurs and investors. However, given that this information is not publicly disclosed our employed methodology of combining company valuation with success rates and development periods may offer first insights into the investment characteristics of this industry.

Third, our analysis only captures value arising from the lead product. Biopharma companies in our sample frequently develop numerous drugs at the same time. Therefore, a more detailed modeling technique capturing the further product portfolio's value is necessary to more realistically estimate investment multiples and returns. However, our assumption of only considering the development stage of the lead product may account for most of a company's value given that products usually share a similar technology or mechanism of action. Consequently, if the lead product fails a development stage, the likelihood of the other products failing could be similarly high. Moreover, early-stage developments of additional indications for a company's lead drug may not be disclosed. Therefore, data on the total number of indications may have been missing and consequently bias results. Nevertheless, this effect is assumed to be minor given that a company's main value driver remains the lead drug's first (most advanced) indication. 
Finally, our methodology projected overall negative returns for the Phase 3 to FDA approval investment period. Valuation of companies in the Approved development stage also includes products that have already been on the market for some years and could consequently face loss of exclusivity. As a result, our sample may underestimate Biopharma company valuation right after FDA approval, which thereby also underestimates returns.

\section{Author Contributions}

DM: data collection, statistical analysis, visualization, writing, and editing. HY: data collection, statistical analysis, supervision, and review. TA: data collection and editing. TM: supervision, editing, and review.

\section{Funding}

Open Access funding enabled and organized by Projekt DEAL. Not applicable.

\section{Declarations}

\section{Conflict of interest}

The authors declare no conflict of interest.

\section{Open Access}

This article is licensed under a Creative Commons Attribution 4.0 International License, which permits use, sharing, adaptation, distribution and reproduction in any medium or format, as long as you give appropriate credit to the original author(s) and the source, provide a link to the Creative Commons licence, and indicate if changes were made. The images or other third party material in this article are included in the article's Creative Commons licence, unless indicated otherwise in a credit line to the material. If material is not included in the article's Creative Commons licence and your intended use is not permitted by statutory regulation or exceeds the permitted use, you will need to obtain permission directly from the copyright holder. To view a copy of this licence, visit http://creativecommons.org/licenses/by/4.0/.

\section{Supplementary Information}

The online version contains supplementary material available at https:// doi.org/10.1007/s43441-021-00364-y.

\section{References}

1. Bansal R, De Backer R, Ranade V. What's behind the pharmaceutical sector's M\&A push. 2018.

2. Dominguez LW, Willis JS. Research and development costs of new drugs. JAMA. 2020;324:516-516.

3. Meyers AD, Hurley P. Bioentrepreneurship education programmes in the United States. J Commer Biotechnol. 2008;14:2-12.

4. Lavrynenko A, Shmatko N, Meissner D. Managing skills for open innovation: the case of biotechnology. Manag Decis. 2018. https:// doi.org/10.1108/MD-04-2017-0301.
5. Michaeli DT, Yagmur HB, Achmadeev T, et al. Value drivers of development stage biopharma companies. Eur J Health Econ. 2022. https://doi.org/10.1007/s10198-021-01427-5

6. Cartwright H, Piper N, Ahmed T. IQVIA pharma deals: half-year review of 2020. 2020.

7. Geilinger U, Leo C, Bujak E. HBM Pharma/Biotech M\&A Report 2020. 2020.

8. Guo R-J, Lev B, Zhou N. The valuation of biotech IPOs. J Acc Audit Financ. 2005;20:423-59.

9. Arnold K, Coia A, Saywell S, Smith T, Minick S, Löffler A. Value drivers in licensing deals. Nat Biotechnol. 2002;20:1085-9.

10. Strömsten T, Waluszewski A. Governance and resource interaction in networks. The role of venture capital in a biotech start-up. J Bus Res. 2012;65:232-44.

11. Wong $\mathrm{CH}$, Siah KW, Lo AW. Estimation of clinical trial success rates and related parameters. Biostat Oxf Engl. 2019;20:273-86.

12. Hay M, Thomas DW, Craighead JL, Economides C, Rosenthal J. Clinical development success rates for investigational drugs. Nat Biotechnol. 2014;32:40-51.

13. DiMasi JA, Feldman L, Seckler A, Wilson A. Trends in risks associated with new drug development: success rates for investigational drugs. Clin Pharmacol Ther. 2010;87:272-7.

14. Kola I, Landis J. Can the pharmaceutical industry reduce attrition rates? Nat Rev Drug Discov. 2004;3:711-6.

15. Takebe T, Imai R, Ono S. The current status of drug discovery and development as originated in United States Academia: the influence of industrial and academic collaboration on drug discovery and development. Clin Transl Sci. 2018;11:597-606.

16. Paul SM, Mytelka DS, Dunwiddie CT, Persinger CC, Munos BH, Lindborg SR, Schacht AL. How to improve R\&D productivity: the pharmaceutical industry's grand challenge. Nat Rev Drug Discov. 2010;9:203-14.

17. Hermosilla M. Rushed innovation: evidence from drug licensing. Manag Sci. 2020;67:257-78.

18. Grabowski H, Vernon J, DiMasi JA. Returns on research and development for 1990s new drug introductions. Pharmacoeconomics. 2002;20(Suppl 3):11-29.

19. Rooswinkel R, Mulder G-J, van Deventer S. Acquiring orphans. Nat Biotechnol. 2014;32:213-6.

20. Meekings KN, Williams CSM, Arrowsmith JE. Orphan drug development: an economically viable strategy for biopharma R\&D. Drug Discov Today. 2012;17:660-4.

21. Sasinowski FJ, Panico EB, Valentine JE. Quantum of effectiveness evidence in FDA's approval of orphan drugs: update, July 2010 to June 2014. Ther Innov Regul Sci. 2015;49:680-97.

22. Mills M, Michaeli D, Miracolo A, Kanavos P. HTA4 clinical development and HTA approval of MULTI-indication Oncology Products: evidence from Germany, France, England, Scotland, the US, Canada, and Australia. Value Health. 2020;23:S403.

23. Michaeli D, Mills M, Kanavos P. PCN251 an econometric analysis of launch determinants for Multi-Indication Oncology Products. Value Health. 2020;23:S467.

24. Mills M, Miracolo A, Michaeli D, Kanavos P. PNS73 payer perspectives on pricing of Multi-Indication Products. Value Health. 2020;23:S655.

25. Bach PB. Indication-specific pricing for cancer drugs. JAMA 2014;312:1629-30.

26. de Av C, Rp D, Bl H, Rr B. Efficacy of immunobiologic and small molecule inhibitor drugs for psoriasis: a systematic review and metaanalysis of randomized clinical trials. Drugs RD. 2017. https://doi. org/10.1007/s40268-016-0152-x.

27. Qiu M, Xu Z, Gao W, Xiong M, Wen X, Zhu W, Zhou X, Yu M. Fourteen small molecule and biological agents for psoriatic arthritis: a network meta-analysis of randomized controlled trials. Medicine. 2020;99:e21447. 
28. Gurevich EV, Gurevich VV. Beyond traditional pharmacology: new tools and approaches. Br J Pharmacol. 2015;172:3229.

29. Makurvet FD. Biologics vs. small molecules: drug costs and patient access. Med Drug Discov. 2021;9:100075.

30. Carr DR, Bradshaw SE. Gene therapies: the challenge of superhigh-cost treatments and how to pay for them. Regen Med. 2016;11:381-93.

31. Hodgson J. Refreshing the biologic pipeline 2020. Nat Biotechnol 2021;1-9.

32. Giniatullina A, Boorsma M, Mulder G-J, van Deventer S. Building for big pharma. Nat Biotechnol. 2013;31:284-7.

33. Ladanie A, Schmitt AM, Speich B, et al. Clinical trial evidence supporting US Food and Drug Administration approval of novel cancer therapies between 2000 and 2016. JAMA Netw Open. 2020;3:e2024406.
34. Dusetzina SB, Huskamp HA, Keating NL. Specialty drug pricing and out-of-pocket spending on orally administered anticancer drugs in Medicare Part D, 2010 to 2019. JAMA. 2019;321:2025-7.

35. Prasad V, De Jesús K, Mailankody S. The high price of anticancer drugs: origins, implications, barriers, solutions. Nat Rev Clin Oncol. 2017;14:381-90.

36. Fojo T, Mailankody S, Lo A. Unintended consequences of expensive cancer therapeutics-the pursuit of marginal indications and a me-too mentality that stifles innovation and creativity: the John Conley Lecture. JAMA Otolaryngol-Head Neck Surg. 2014; 140:1225-36.

37. Mailankody S, Prasad V. Five years of cancer drug approvals: innovation, efficacy, and costs. JAMA Oncol. 2015;1:539-40. 